\title{
Epi-letters - how to describe epigenetic signatures
}

Huy Q Dinh ${ }^{1,2}$

From Eighth International Society for Computational Biology (ISCB) Student Council Symposium 2012

Long Beach, CA, USA. 13-14 July 2012

\section{Background}

The concept of a chromatin-based epigenetic code, proposed more than a decade ago, associates specific combinations of chromatin marks with different gene expression states and their maintenance [1]. High-throughput technologies like microarray profiling or next generation sequencing enable us to examine the validity of the concept, by profiling transcriptomes and multiple chromatin marks for many different samples, conditions and organisms. The large amounts of generated data require efficient

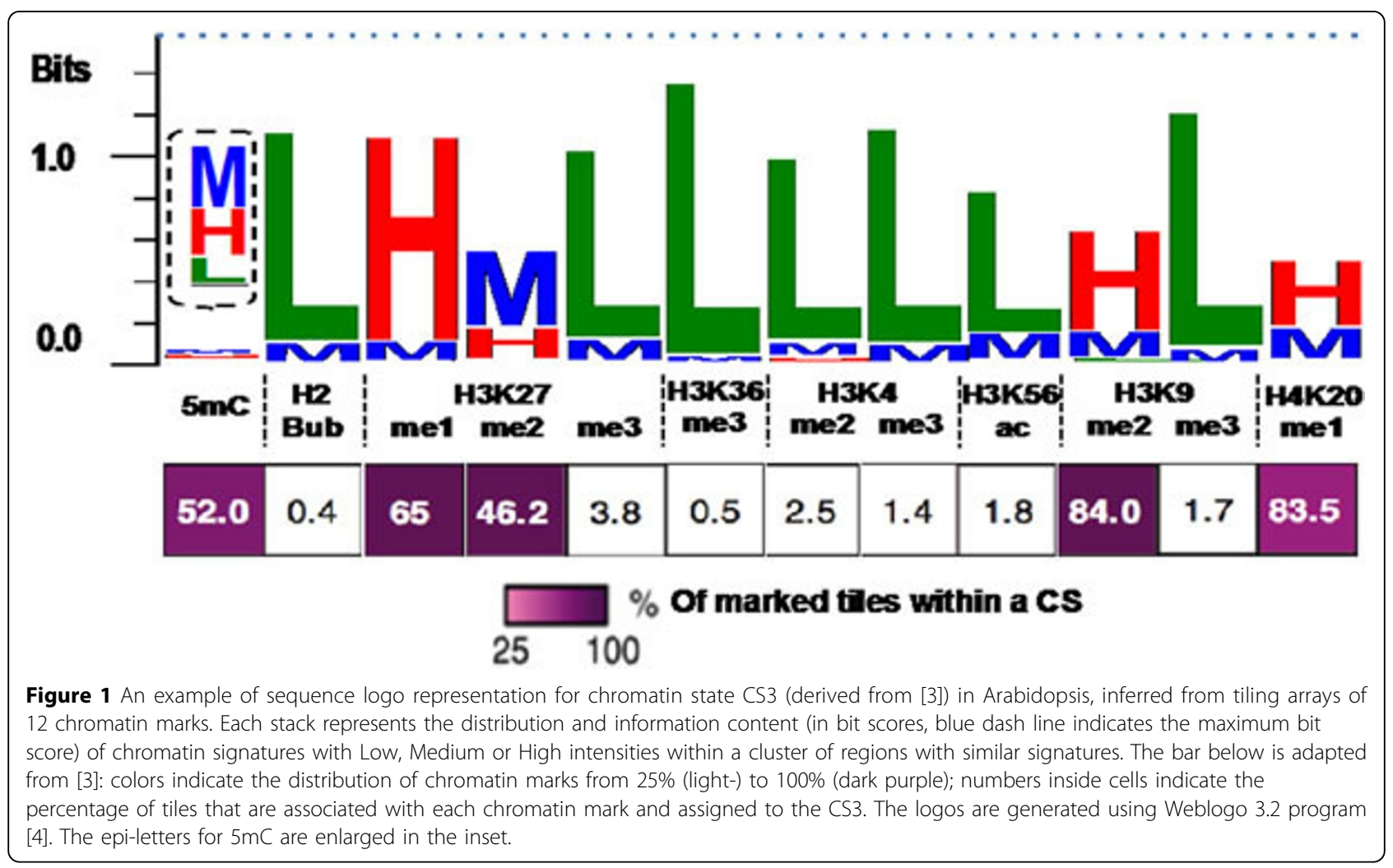

Correspondence: huy.dinh@univie.ac.at

'Center for Integrative Bioinformatics Vienna, Max F. Perutz Laboratories,

University of Vienna, Medical University of Vienna, A-1030 Vienna, Austria

Full list of author information is available at the end of the article 
and instructive computational methods to identify and interpret biologically relevant correlations and to challenge the hypothesis of an epigenetic code.

\section{Results}

Here, I introduce a generally applicable bioinformatic method to group epigenetic information across genomewide chromatin data sets. It automatically classifies the abundance of chromatin-based signals into discrete categories and transforms the categories into so-called epi-letters. Each genomic region can then be represented as a combined string of epi-letters referring to different chromatin marks. This synoptic compilation can be used for further clustering to determine common epigenetic signatures and can be represented applying the concept of the DNA motif sequence logo [2].

I present the results of applying the epi-letter principle using published data [3] from 12 chromatin marks (including DNA methylation) in the model organism Arabidopsis thaliana (an example of representing a chromatin state in Figure 1).

\section{Conclusions}

I propose a new and simple tool for finding and representing epigenetic patterns across genome-wide profiling data of different chromatin marks. I provide a proof-of-concept application with published data, resulting in a classification of epigenetic signatures in Arabidopsis thaliana. The method has also other potentials for de novo discovery and visualization of general genome-wide profiling patterns.

\footnotetext{
Acknowledgement

I thank my PhD advisors Arndt von Haeseler and Ortrun Mittelsten Scheid for interesting discussions and support. The traveling fellowship for participating SCS8/ISMB2012 from Swiss Bioinformatics Institute is greatly acknowledged.
}

\section{Author details}

${ }^{1}$ Center for Integrative Bioinformatics Vienna, Max F. Perutz Laboratories, University of Vienna, Medical University of Vienna, A-1030 Vienna, Austria. ${ }^{2}$ Gregor Mendel Institute of Molecular Plant Biology, Austrian Academy of Sciences, A-1030 Vienna, Austria.

Published: 14 December 2012

\section{References}

1. Jenuwein T, Allis CD: Translating the histone code. Science 2001, 293(5532):1074-1080.

2. Schneider TD, Stephens RM: Sequence logos: a new way to display consensus sequences. Nucleic acids research 1990, 18(20):6097-6100.

3. Roudier F, Ahmed I, Berard C, Sarazin A, Mary-Huard T, Cortijo S, Bouyer D, Caillieux E, Duvernois-Berthet E, Al-Shikhley L, et al: Integrative epigenomic mapping defines four main chromatin states in Arabidopsis. The EMBO journal 2011, 30(10):1928-1938.

4. Crooks GE, Hon G, Chandonia JM, Brenner SE: WebLogo: a sequence logo generator. Genome research 2004, 14(6):1188-1190.
doi:10.1186/1471-2105-13-S18-A4

Cite this article as: Dinh: Epi-letters - how to describe epigenetic signatures. BMC Bioinformatics 2012 13(Suppl 18):A4.

\section{Submit your next manuscript to BioMed Central and take full advantage of:}

- Convenient online submission

- Thorough peer review

- No space constraints or color figure charges

- Immediate publication on acceptance

- Inclusion in PubMed, CAS, Scopus and Google Scholar

- Research which is freely available for redistribution

Submit your manuscript at www.biomedcentral.com/submit
C Biomed Central 